\title{
Statistics for clinical nursing practice: an introduction
}

\author{
Claire M Rickard RN BN GDN(CritCare), PhD, MRCNA \\ Research Centre for Clinical and Community Practice Innovation, and \\ School of Nursing and Midwifery \\ Griffith University, Nathan, QLD 4111, Australia
}

\begin{abstract}
Summary
Difficulty in understanding statistics is one of the most frequently reported barriers to nurses applying research results in their practice. Yet the amount of nursing research published each year continues to grow, as does the expectation that nurses will undertake practice based on this evidence. Critical care nurses don't need to be statisticians, but they do need to develop a working knowledge of statistics so they can be informed consumers of research and so practice can evolve and improve. For those undertaking a research project, statistical literacy is required to interact with other researchers and statisticians, so as to best design and undertake the project. This article is the first in a series that guides critical care nurses through statistical terms and concepts relevant to their practice.
\end{abstract}

\section{Keywords}

\section{Statistics}

Nursing

Evidence-based practice

Critical Care

Intensive Care

\section{Introduction}

'Statistics' can simply mean something expressed in numbers. For example, Our unit has 1200 admissions per year. The average length of stay is 3.2 days. Over $80 \%$ of our nurses have a critical care qualification. In a related meaning, 'statistics' are the tests that examine data from subsets of people, and tell us how likely that this reflects the real situation for the whole population. This introductory article aims to set the scene as to why critical care nurses need statistics and to overcome some common misconceptions.

Difficulty in understanding statistics is one of the most frequently reported barriers to nurses applying research results in their practice. ${ }^{1}$ Yet the amount of nursing research published each year continues to grow, as does the expectation that nurses will undertake practice based on this evidence. Critical care nurses don't need to be statisticians, but they do need to develop a working knowledge of statistics so they can be informed consumers of research and so practice can evolve and improve. For those undertaking a research project, statistical literacy is required to interact with other researchers and statisticians, so as to best design and undertake the project.

\section{"Statistics is all about maths, I'm no good at maths!"}

Many people in the community have insecurities about maths; for many this is a 'hang up' from their school days. Statistical tests are built on mathematical theories, but simply reading and understanding results requires no particular mathematical ability. Acquiring a working knowledge of statistics is achievable by any nurse. Only a small number of the range of statistical terms and tests are used in most studies, and even 
knowing a dozen statistical terms will make 99\% of journal articles fairly clear. Just as one does not need to be totally fluent in French or Italian to recognise 'Merci' or 'Ciao' and understand perfectly well, so too, a little statistics can improve confidence and enjoyment of professional life.

\section{Why statistics?}

One could say that the average critical care nurse is exposed to 10 statistics a day, and 25\% of all statistics are made up. In fact, both of these statistics are made up, but serve to illustrate a point. Statistics are powerful. They grasp the imagination and quantify perception. Statistics are harder to argue with than emotion or opinion alone. If you want to effect change, you are going to need statistics to back up your argument. One of the most powerful statistics for effecting change in nursing showed that each additional patient added to USA nurses' patient load, had an associated increased patient mortality of $7 \%$ (odds ratio [OR], 1.07; 95\% confidence interval [CI], 1.03-1.12). ${ }^{2}$ More nurses, less deaths. This is much harder to argue with than general complaints about overwork and understaffing.

\section{Statistics help us to understand our patients}

Data collected by critical care nurses around Australia and New Zealand told us that almost half (45\%) of our patients have delirium, and that long after they leave hospital, many have no factual memory but strong delirious memories of ICU. ${ }^{3,4}$ These types of statistics raise issues that may be underappreciated, and quantify their frequency and importance. They force us to confront realities, and they challenge us to respond. As the consumer movement continues to grow, we can expect more patients and their loved ones to be aware of the statistics surrounding critical care, and to expect us to be able to discuss this with them in an informed manner.

\section{Statistics help us to understand ourselves as critical care nurses}

We can describe or measure our own performance, explain what we do and understand what makes us different. For years, the contribution of critical care nurses beyond the ICU has been known by us, but not officially recognised or funded. Statistics have demonstrated ICU liaison nurses reduce ICU discharge delays, improve discharge planning and have helped to develop this exciting new career path. $^{5,6}$

\section{Statistics help us to compare options for practice}

How else do we really know whether nursing interventions are effective? Which dressing should we use? How often should we change it? Should we wear sterile, clean or no gloves during the procedure? Statistics tell us that neither replacing intravenous administration sets, or fluids, prior to a week is likely to reduce infection. ${ }^{7,8}$ Statistics are important for decision making in critical care nursing. There are few settings where nurses have to make so many decisions each day as in intensive care units. Gut instinct and experience alone are unreliable, but statistics can guide our decisions, and help us to make the right ones.

\section{Statistics challenge us to rethink our assumptions}

Traditionally arterial lines were thought of as "lower risk" for bloodstream infections compared to central lines; recent data suggests incidence is equivalent and calls for us to rethink our practice and beliefs. ${ }^{9}$ Statistics help us not to be confused or deceived. Not only can statistics help us make good decisions, but also help us avoid making 
bad ones. How do we choose to spend limited resources? All heathcare device manufacturers can provide statistics that support their use. The ability to compare and consider statistical data assists in making informed, objective decisions, and ones that can be defended.

\section{Statistics help us to develop our profession}

Advancing nursing as a profession requires statistics to develop and inform best practice. It is our responsibility to the public, who we serve, to constantly update and improve the body of critical care nursing knowledge. If we don't move forward we will slip backward. There is nothing new about combining caring and statistics. Florence Nightingale, the founder of professional nursing, was committed to statistics and used them effectively to improve practice and lobby for changes to government policy. ${ }^{10}$ Through numbers, she showed that improved sanitary conditions led to reduced deaths, and encouraged the use of benchmarking, even when this showed her own hospital to have the worst mortality.

\section{Statistics can help you in your personal life too}

The general public has difficulty with statistics and media reports often perpetuate this with poor reporting or sensationalist claims. Understanding basic statistics is crucial in everyday life to make decisions, quantify risk, or just understand the news! Recent legislation in many Australian States to display grocery prices per $100 \mathrm{~g}$ shows how standardised statistical data can reduce the confusion and impact of clever marketing.

\section{Statistics teach us to be cautious}

Statistics rarely 'prove' anything and remind us that human life and experiences are complex. Finding out whether 'A causes B' may take many years and several studies, some with conflicting results, and it is important to be able to see the bigger picture, and the answer evolving, rather than leaping on the bandwagon of any one particular finding. This is an important counterpoint to busy critical care environments where confident and definitive answers may be the expectation. Modern statistics packages are a mixed blessing. Any amateur statistician can churn out hundreds of statistics in seconds, with a good chance of finding significant results due to incorrect tests or the large volume of tests performed. Alternately, even a technically perfect statistical analysis will not make up for problems in how the data were collected. When reading study results, always ask questions, question assumptions and be slow to draw conclusions.

\section{Statistics are not going to go away}

The expectation that critical care nurses can understand and use statistics is only going to grow. For those who have been avoiding it until now, this series of articles provides the perfect opportunity to conquer concepts you will face for the rest of your career. The first step in learning statistics is not mathematical, but rather psychological. Accepting the importance of statistics; overcoming any fear of numbers and investing a small amount of effort are all that is required. Once you have grasped a concept, just reading and discussing the articles in ACC and other journals with your colleagues will ensure you keep that knowledge. Like anything else, it takes practice and the more you do it the easier it gets. Critical care nurses can calculate drug doses, interpret numerous physiological parameters, and coordinate complex care; compared to that, statistics should be a walk in the park! 


\section{References}

1. Retsas A, Nolan M. Barriers to nurses' use of research: an Australian hospital study. Int J Nurs Stud 1999;36(4):335-43.

2. Aiken LH, Clarke SP, Sloane DM, Sochalski J, Silber JH. Hospital nurse staffing and patient mortality, nurse burnout, and job dissatisfaction. JAMA 2002;288(16):1987-93.

3. Roberts B, Rickard CM, Rajbhandari D, Turner G, Clarke J, Hill D, Tauschke C, Chaboyer W, Parsons R. Multicentre study of delirium in ICU patients using a simple screening tool. Aust Crit Care 2005;18(1):6-16,7,10,15passim.

4. Roberts BL, Rickard CM, Rajbhandari D, Reynolds P. Factual memories of ICU: recall at two years post-discharge and comparison with delirium status during ICU admission - a multicentre cohort study. J Clin Nurs 2007;16(9):1669-77.

5. Chaboyer W, Thalib L, Foster M, Elliott D, Endacott R, Richards B. The impact of an ICU liaison nurse on discharge delay in patients after prolonged ICU stay. Anaesth Intensive Care 2006;34(1):55-60.

6. Chaboyer W, Foster M, Kendall E, James H. The impact of a liaison nurse on ICU nurses' perceptions of discharge planning. Aust Crit Care 2004;17(1):25-32.

7. Rickard CM, Lipman J, Courtney M, Siversen R, Daley P. Routine changing of intravenous administration sets does not reduce colonization or infection in central venous catheters. Infect Control Hosp Epidemiol 2004;25(8):650-5.

8. Rickard CM, Keene LJ, Vannapraseuth B, Rambaldo S, McGrail MR, Ray-Barruel G. A cross-sectional study investigating the relationship between intravenous infusate colonisation and fluid container hang time. J Clin Nurs in press; accepted 12/06/2008.

9. Koh DB, Gowardman JR, Rickard CM, Robertson IK, Brown A. Prospective study of peripheral arterial catheter infection and comparison with concurrently sited central venous catheters. Crit Care Med 2008;36(2):397-402. Erratum: 36(4):1394.

10. McDonald L. Florence Nightingale and the early origins of evidence-based nursing. Evid Based Nurs 2001;4(3):68-9. 